\title{
High Reynolds Number Thermal Stability Experiments
}

\author{
Jessica M. Emens, "Sarah P. Brown, ${ }^{\dagger}$ and Robert A. Frederick, Jr. $^{\ddagger}$ \\ University of Alabama in Huntsville, Huntsville, Alabama, 35899 \\ and \\ A. John Wood ${ }^{\S}$ \\ Stanhope-Seta, Chertsey, Surrey, England, KT16 8AP
}

\begin{abstract}
This work represents preliminary thermal stability results for liquid hydrocarbon fuels. High Reynolds Number Thermal Stability experiments with Jet A and RP-1 resulted in a quantitative measurement of the thermal stability. Each fuel flowed through a heated capillary tube that held the outlet temperature at $290^{\circ} \mathrm{C}$. An optical pyrometer measured the surface temperature of the tube at 12 locations as a function of time. The High Reynolds Number Thermal Stability number was then determined using standards published by the American Society for Testing and Materials. The results for Jet A showed lower thermal stability than similar tests conducted at another facility. The RP-1 results are the first reported using this technique. Because the temperature rise on the capillary tube during testing for the RP-1 fuels was not significant, a new standard for the testing conditions should be developed for these types of fuels.
\end{abstract}

\section{Nomenclature}

$H N-9=$ HiReTS number using 9 pyrometer positions

$H N-12=$ HiReTS number using 12 pyrometer positions

$n=$ index of pyrometer measurement position

$T=$ Temperature during a test

$T_{\text {Final }}=$ Final temperature recorded during a test

$T_{\min }=$ Minimum temperature recorded during a test

$T-T_{\min }=$ Delta temperature

\section{Introduction}

$\mathrm{T}$ his paper presents thermal stability results for two liquid hydrocarbon fuels. There are three objectives of this initial work. The first is to verify the initial operation of a High Reynolds Number Thermal Stability (HiReTS) tester and e stablish r epeatable operation. The second is to test Je $t$ A fuel that has previous results a t similar conditions for a reproducibility evaluation. The third is to test RP-1 to evaluate the usefulness of the HiReTS method for this fuel class.

\section{A. What is Thermal Stability and Why is it Important?}

Thermal stability describes the effect of temperature on hydrocarbon fuels. When a fuel reaches the thermal decomposition temperature, its chemical structure begins to break down and it deposits a hard film on engine parts as well as other plumbing within the propulsion system in a process called coking. ${ }^{1}$ A thermally unstable fuel reaches this point at relatively low temperatures and short time within the heated environment.

* Graduate Research Assistant, Department of Mechanical and Aerospace Engineering, 5000 T echnology Drive, AIAA Student Member

${ }^{\dagger}$ Graduate Research Assistant, Department of Mechanical and Aerospace Engineering, 5000 Technology Drive, AIAA Student Member

$\ddagger$ Associate Professor, Department of Mechanical and Aerospace Engineering, 5000 Technology Drive, ALAA Associate Fellow

${ }^{\S}$ Principle Design Engineer, Research and Development, Stanhope-Seta, London Street 
Newer rockets are attempting to use kerosene and other hydrocarbon fuels instead of more traditional fuels. ${ }^{1}$ The hydrocarbon fuels have the advantage of being cheaper, safer, and allowing the systems they are used in to be reused. However, for better performance, rocket engines are being asked to perform at higher chamber pressures. The higher pressures lead to a nearly proportional increase in wall heat flux in the thrust chamber. The fuels are being subjected to higher and higher temperatures before actual combustion both in an attempt to pre-heat the fuel for better e fficiency a s well as u sing the relatively cooler fuel to cool the various hotter $p$ arts of the propulsion system (regenerative cooling). ${ }^{2}$

There are two main effects of the coking process. One is that as the coke buildup becomes larger, it is harder for the liquid fuel to pass through the pipes. Thus, there are greater pressure losses through the pipes and the efficiency of the engine goes down. The second effect is that the carbon deposits act as a thermal insulator between the hotter outside tube (warmed by other engine parts) and the relatively cooler fuel, which is being used to cool the hot engine parts in certain applications. Thus, the wall temperature tends to increase until material failure. ${ }^{2} \mathrm{~A}$ fuel with higher thermal stability will reduce the amount of deposits thus requiring less engine maintenance as well as higher reliability. This directly reduces costs for both maintenance and operation.

\section{B. Measuring Thermal Stability}

To determine the thermal stability of a fuel, several test methods are available for use. Thermal stability test methods can be divided into three categories: static, flowing, and engineering. ${ }^{3}$ Static tests involve heating a fixed amount of fuel, which is either open or closed to the air with additional oxygen available. Static tests require small amounts of fuel with testing times of hours. Flowing tests consist of laminar, transitional, or turbulent flow through or around a heated tube. The tube can be heated to provide a constant heat flux, constant bulk, or constant wall temperature with no additional oxygen available. ${ }^{3}$ Flowing tests require gallons of fuel and take hours to complete. Engineering tests are specifically designed to simulate conditions found in aircraft. These systems are capable of making realistic simulations of aircraft fuel systems at the same conditions that would be seen in an actual aircraft system. These test require significantly more fuel and take days to weeks to complete. ${ }^{3}$

The test method chosen for the testing at the University of Alabama in Huntsville (UAH) is the HiReTS tester. The HiReTS device was developed by Shell Research Limited to provide a small-scale tester that would operate under realistic conditions to include turbulent flow. ${ }^{4}$ The HiReTS is currently manufactured by Stanhope-Seta under a license agreement from Shell Research. This tester fits within the characteristics for a flowing test and is described in detail in the Approach section of this paper.

\section{What Makes the HiReTS Tester Different?}

In contrast to other flow tests, the HiReTS machine tests fuel in turbulent flow conditions with Reynolds number of 5000 or more, which more accurately reproduces the conditions found in engines. A small fuel quantity of $5 \mathrm{~L}$ is used to perform the test. Hence, quick and regular results can be obtained. The results are shown in real time and a quantitative result is produced at the end without the need for human intervention or interpretation. The buildup of carbon deposits over time may be analyzed. This recorded profile may be used to determine the effect of additives if they are added part way through a test or compared directly with a baseline fuel.

\section{Approach}

\section{A. HiReTS Machine}

The HiReTS machine is shown in Fig. 1. It is contained within a standard 19 inch rack and includes: a computer, keyboard, liquid crystal display, printer, as well as the items that are required to test the thermal stability of fuels. 
A flow diagram of the HiReTS tester is shown in Fig. $2 .^{5}$ The fluid first passes through a filter contained in the sample vessel where the initial temperature is recorded. Then a pump moves the fluid at flow rates from $20-50 \mathrm{~mL} / \mathrm{min}$ through a manometeric unit. Afterwards the fluid is passed through a vertically held stainless steel tube called a capillary that is heated electrically by bus bars located at the ends of the tube. The capillary is heated to maintain a set temperature of the fuel outlet. The temperature can be set within in the range of $250-350{ }^{\circ} \mathrm{C}$. As the fuel is heated, deposits are formed along the inside walls of the capillary. The deposits act as insulators increasing the outer wall temperatures of the capillary tube. The outer wall of the capillary tube is painted black to control the emissivity and its temperature is measured by a non-contact thermometer or pyrometer. As the fluid exits the capillary, a thermister measures the temperature. The fluid is then cooled by a counter flow heat exchanger (waste sample cooler) to a set point of $50{ }^{\circ} \mathrm{C}$. The backpressure valve maintains the system pressure at $2 \mathrm{MPa}$ or higher to prevent the fuel from boiling. The bypass valve is set to prevent over pressure in the event of a blockage and reduce the pressure after a test.

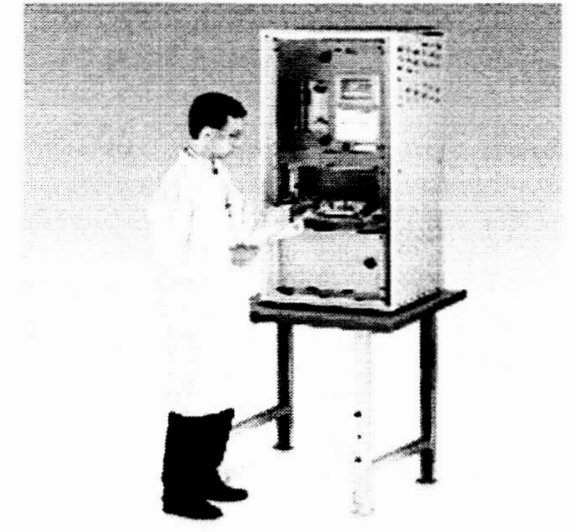

Figure 1. Stanhope-Seta HiReTS Machine

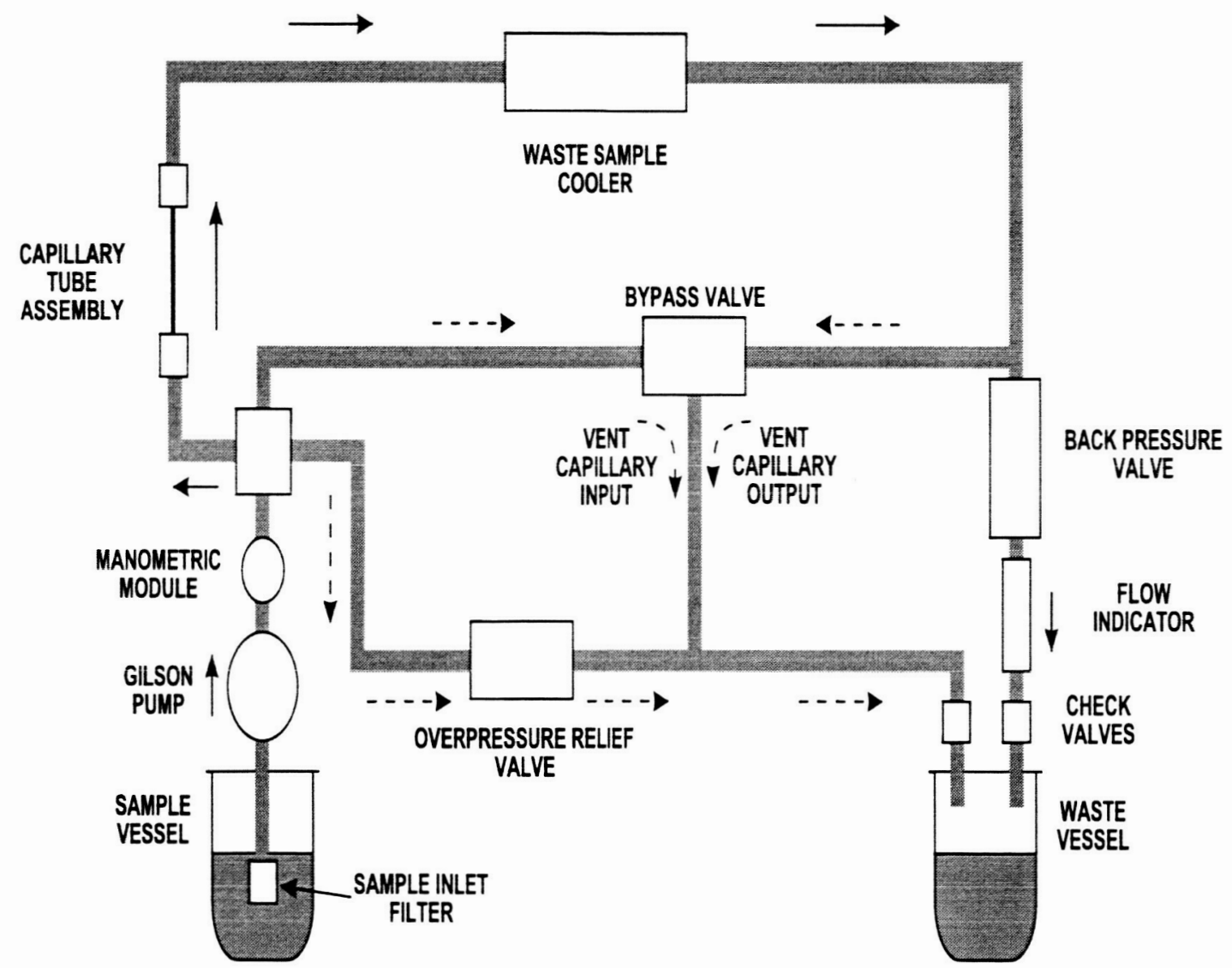

Figure 2. HiReTS Flow Diagram ${ }^{5}$ 
A diagram of the capillary section of the HiReTS machine is shown in Fig. 3. The capillary is $152.5 \pm 0.2 \mathrm{~mm}$ in total length with the painted section covering a length of 112.5 $\mathrm{mm}$. The inner diameter is $0.260 \mathrm{~mm}$ to $0.300 \mathrm{~mm}$ and the outer diameter is $1.588 \mathrm{~mm}$ to $1.638 \mathrm{~mm}{ }^{6}$ The datum position is the position where the tube meets the bus bar. The first measured position, the thermal start position, is located $1 \mathrm{~mm}$ below the datum position. The pyrometer measures temperature every 5 minutes at each position located $2.5 \mathrm{~mm}$ below the previous position for a total of 12 positions. The distance between the positions is called the step distance. The total length scanned by the pyrometer is $28.5 \mathrm{~mm}$. A complete scan is finished once the pyrometer has measured temperatures at each position and returned to the datum position.

The output of the HiReTS tester is a called a HiReTS number or HN. This number is determined by subtracting the minimum temperature, $T_{\min }$, recorded during the test from $T_{\text {Final }}$, the last temperature measured. These delta temperatures are taken at each position measured by the pyrometer. The $\mathrm{HN}$ is the sum of the 12 delta temperatures shown in Eq. 1.

The $\mathrm{HN}$ is an indication of the amount of deposits formed within the tube and is higher for fuels that are thermally unstable. As more deposits form on the walls of the capillary, the temperatures of the walls increase because the deposits act

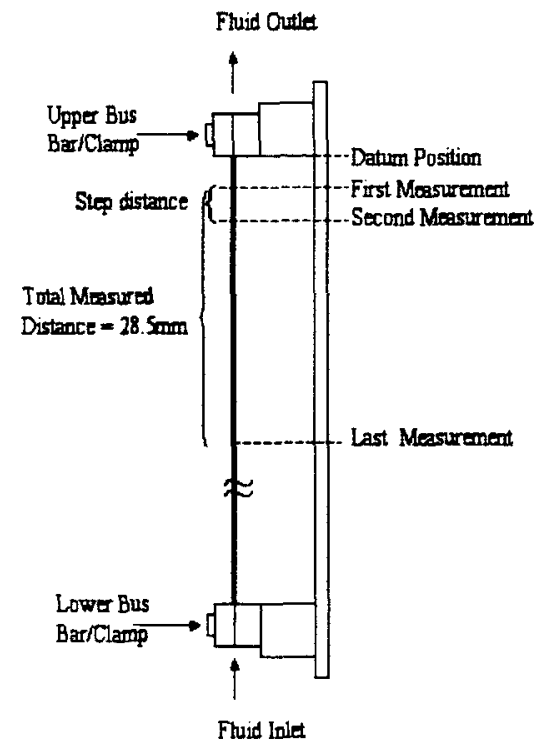

Figure 3. Diagram of Capillary Section as insulators. The deposits prevent the energy put into the capillary walls from the bus bars from dissipating into the fluid, thus, the wall temperatures increase. The higher temperatures increase the value of the HN. The pass/fail HN number is 1000 , where a number under 1000 indicates a thermally stable fuel for aviation fuels. ${ }^{4}$

$$
H N=\sum_{n=1}^{12}\left(T_{\text {Final }}-T_{\min }\right)_{n}
$$

\section{B. Fuels}

The fuels initially tested with the HiReTS tester include Jet A and R P-1, both provided by Wright Patterson Airforce Base (WPAFB). The Jet A (POSF-3084) was chosen since it has been previously tested with a HiReTS machine at WPAFB. ${ }^{7}$ The testing sequence shown in Table 1 shows the fuels were rotated for each test, where Fuel $A$ is the Jet A and Fuel B is RP-1.

Table 1. Testing Sequence

\begin{tabular}{lcc}
\hline & Test 1 & Test 2 \\
\hline Day 1 & Fuel A & Fuel B \\
Day 2 & Fuel A & Fuel B
\end{tabular}

Alternating the fuels through the HiReTS tester is to ensure that the temperature of the environment and cleanliness of the tester do not influence the results. 


\section{Operation Conditions}

The standard operating conditions (SOC) as in the ASTM D6811 are detailed in Table $2{ }^{6}$

Table 2. Standard operating conditions from ASTM D6811

\begin{tabular}{lll}
\hline Description & Value & Units \\
\hline Capillary fluid exit temperature & 290 & ${ }^{\circ} \mathrm{C}$ \\
Flow rate & 35 & $\mathrm{~mL} / \mathrm{min}$ \\
Thermal start position & 1.0 & $\mathrm{~mm}$ \\
Measurement step distance & 2.5 & $\mathrm{~mm}$ \\
Time per measurement & 1 & $\mathrm{~s}$ \\
Measurements per scan & 12 & \\
Number of scans & 13 or 25 & \\
Time between scans & 300 & $\mathrm{~s}$ \\
System cooling time & 300 & $\mathrm{~s}$ \\
Sample time & 14 & $\mathrm{~s}$ \\
Test time & 65 or 125 & $\mathrm{~min}$ \\
Sample size & 3 or 5 & $\mathrm{~L}$ \\
\hline
\end{tabular}

\section{Results and Discussion}

The HN values for all tests are shown in Table 3. Each fuel is tested at the SOC conditions outlined by ASTM D6811 for a 125 -minute test with 25 scans and $5 \mathrm{~L}$ of fuel.

Table 3. HN values for each test

\begin{tabular}{lllcl}
\hline Test & Fuel & $H N-12$ & $H N-9$ & Comment \\
\hline 1 & Jet A & 911.1 & 843.5 & Extended test \\
2 & RP-1 & 27.5 & - & Inaccurate temperature reading \\
3 & Jet A & 606.1 & 558.7 & - \\
4 & RP-1 & 22.9 & - & - \\
\hline
\end{tabular}

The $H N-12$ is the $H \mathrm{~N}$ found by 12 pyrometer positions. The $H N-9$ values are determined for the comparison with the data from WPAFB. The tester at WPAFB (Prototype HiReTS Fuel Tester, No. 2, US version) contained 9 pyrometer positions as the default conditions for determining the $\mathrm{HN}{ }^{7}$ The pyrometer measurements start $1 \mathrm{~mm}$ below the upper bus bar with a step distance of $2.5 \mathrm{~mm}$ covering a total distance of $21 \mathrm{~mm}$. To compare the data from the Stanhope-Seta HiReTS machine, the temperature measurements at the last 3 positions are ignored to determine the $H N-9$.

The comment column denotes an error that occurred during testing that influenced results. In the case for Test 1 of the Jet A, the test was stopped due to an equipment error and restarted without inserting a new capillary tube. The result of this is the tube already contained deposits when the new test started resulting in the capillary experiencing an extended test duration. In the case for Test 2 of the RP-1, the initial results indicated a temperature measurement of $168.0^{\circ} \mathrm{C}$ at position of $28.5 \mathrm{~mm}, 60$ minutes into the test. This measurement is an error since the pyrometer can only measure a minimum temperature of $216.4^{\circ} \mathrm{C}$. The temperature of $168.0^{\circ} \mathrm{C}$ then became the minimum reading for the position of $28.5 \mathrm{~mm}$ causing the reported $\mathrm{HN}$ to be higher, a value of 180.7 . To correct this temperature the previous temperature measurement taken 5 minutes before is substituted as the temperature to establish a good estimate for the $\mathrm{HN}$ of this test. Resetting this data point does not affect the true HiReTS number unless the minimum temperature at that station happened to occur at that time. Examining the temperature at that station before and after the dropout does not lead to that possibility. The result is 27.5 , the number shown in the table is therefore an accurate HR-12 number. 
Figures 3 and 4 shown below are graphs of the HiReTS temperature data from the Jet A and RP-1.

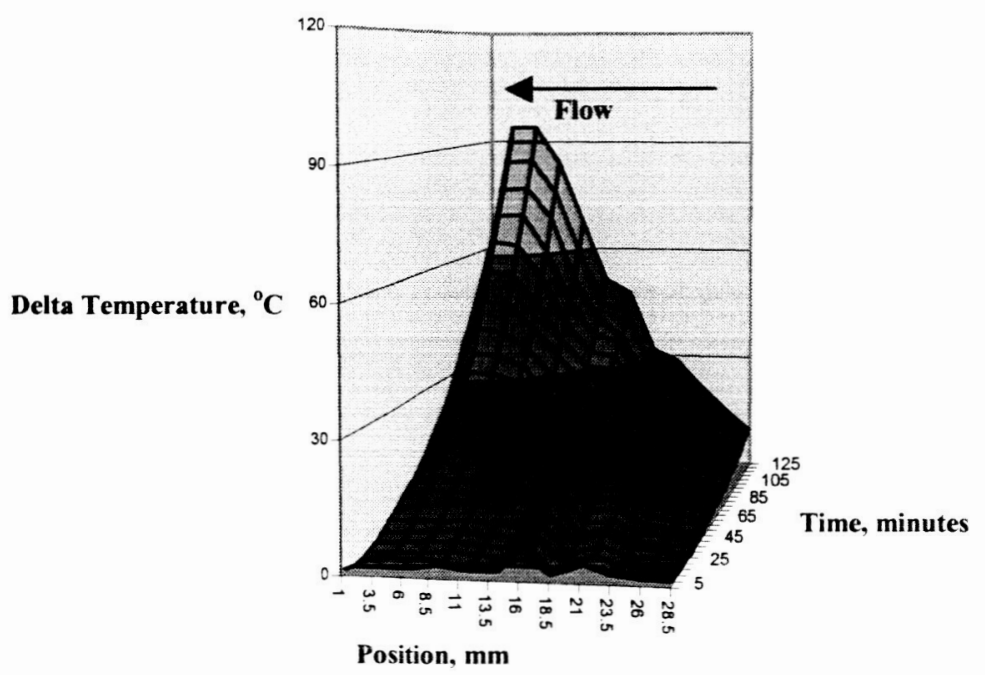

Figure 3. Jet A, Test 3

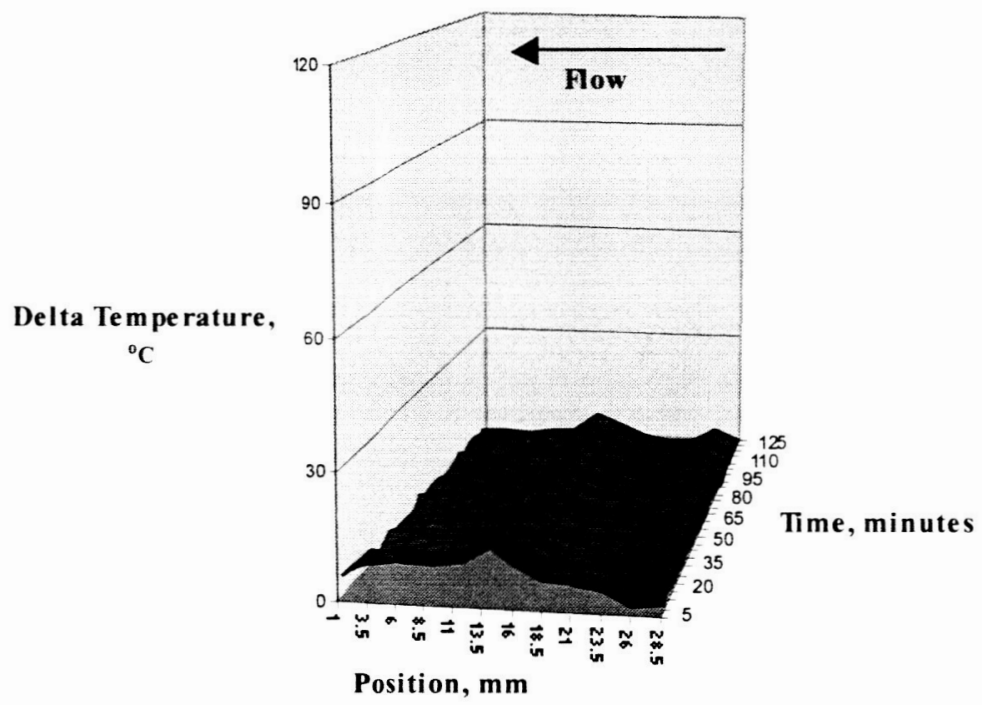

Figure 4. RP-1, Test 4

The graphs show position versus time versus delta temperature, where delta temperature is $T-T_{\min }$ at the corresponding time step. The graph of Jet A, Figure 3), shows a general temperature increase over time at each station indicating an increase in the formation of deposits throughout the test. Also, temperatures increase more at the fuel outlet end of the capillary. Comparing the graphs for Jet A and RP-1 (Figure 4) shows the thermal stability for RP-1 is greater than the Jet A. The results for the RP-1 show no significant changes in temperature profiles at the SOC. Therefore to measure changes or improvements in RP-1 thermal stability, the SOC must be modified to produce larger temperature responses. 
Comparing the Jet A results of Test 1 and Test 3, it is evident that the $\mathrm{HN}$ is higher for Test 1 . This higher HN is consistent with the extended test time the capillary tube experienced. The results for the Jet A from WPAFB are a mean HN of $344 \pm 66$ obtained from 6 tests. ${ }^{7}$ Comparing this $\mathrm{HN}$ to the $\mathrm{HN}$ of 558.7 found at UAH, the HN at UAH is higher than the previously tested value for the HN found at WPAFB. The possible reasons for this include the aging of the fuel, the use of a tester manufactured from different companies, and the use of capillary tubes from different suppliers.

\section{Conclusions}

More tests are required to confirm repeatability of the HiReTS tester. The $\mathrm{HN}$ for Jet A was not reproducible compared with the results found at WPAFB possibly due to the difference in the fuel age, the use of different testers, and/or difference in the capillary tubes used. The tests of RP-1 conducted at the SOC outlined by ASTM did not produce HNs that would be sensitive to improvements in thermal stability of RP-1. Thus, continued testing of RP-1 will require the development of new SOC.

\section{Acknowledgments}

This work is sponsored by Grant NCC8-200 through NASA Marshall Space Flight Center. Thanks to Tim Edwards for supplying the fuels used in these tests. Jordon Farina and Tony Hall of UAH are acknowledged for laboratory setup and assistance.

\section{References}

'Flinn, Edward D., "Kerosene Fuels New Engine Ideas," Aerospace America, October 2002, p. 20-22.

${ }^{2}$ Giovanetti, A. J., Spadaccini, L. J., and Szetela, E. J., "Deposit Formation and Heat Transfer in Hydrocarbon Rocket Fuels." NASA CR-168277, October 1983.

${ }^{3}$ Heneghan, S. P., Zabarnick, S., Ballal, D. R. and Harrison, W. E., "JP-8+100: The Development of High Thermal Stability Jet Fuel," Journal of Energy Resources Technology, Vol. 118, September 1996, pp.170-179.

${ }^{4}$ Bauldreay, J. M., Heins, R. J., Houlbrook, G., and Smith, J., "High Reynolds Number Thermal Stability (HiReTS) Rig for Realistic, Rapid Evaluation of Distillate Fuel Thermal Oxidative Stability," $\sigma^{\text {th }}$ International Conference on Stablity and Handling of Liquid Fuels, Vancouver, B.C. Canada, October 13-17, 1997.

5 "High Reynolds Number Thermal Stability (HiReTS) Tester: Users Manual," Stanhope-Seta, Chertsey, Surrey, UK, viewed 2004

${ }^{6}$ American Society for Testing and Materials, Designation: D 6811-02, "Standard Test Method for Measurement of Thermal Stability of Aviation Turbine Fuels under Turbulent Flow Conditions (HiReTS Method)".

${ }^{7}$ Zabarnick, S., Mick, M. S., and Anderson, S. D., "HiReTS Evaluation Studies at Wright-Patterson Air Force Base," University of Dayton Research Institute, Aerospace Mechanics Division, Dayton, OH \& Airforce Research Laboratory (AFRL/PRSF), Wright-Patterson AFB, OH (unpublished). 
Robert Frederick UAH

From:

Sent:

To:

Subject:
Eric.H. Hyde [Eric.Hyde@msfc.nasa.gov]

Monday, June 21, 2004 9:13 AM

frederic@mae.uah.edu

Re: UAH PRC Paper Approval

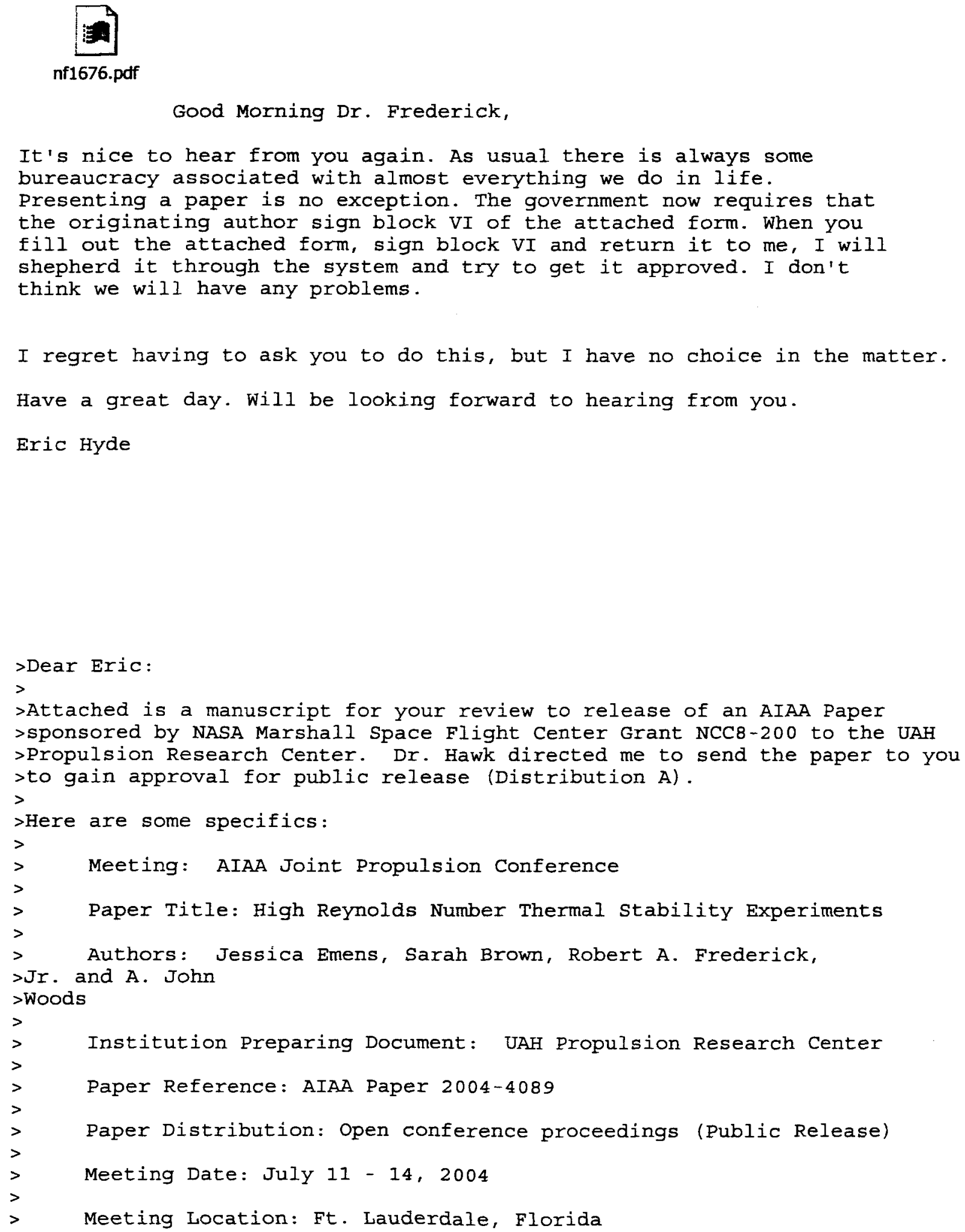




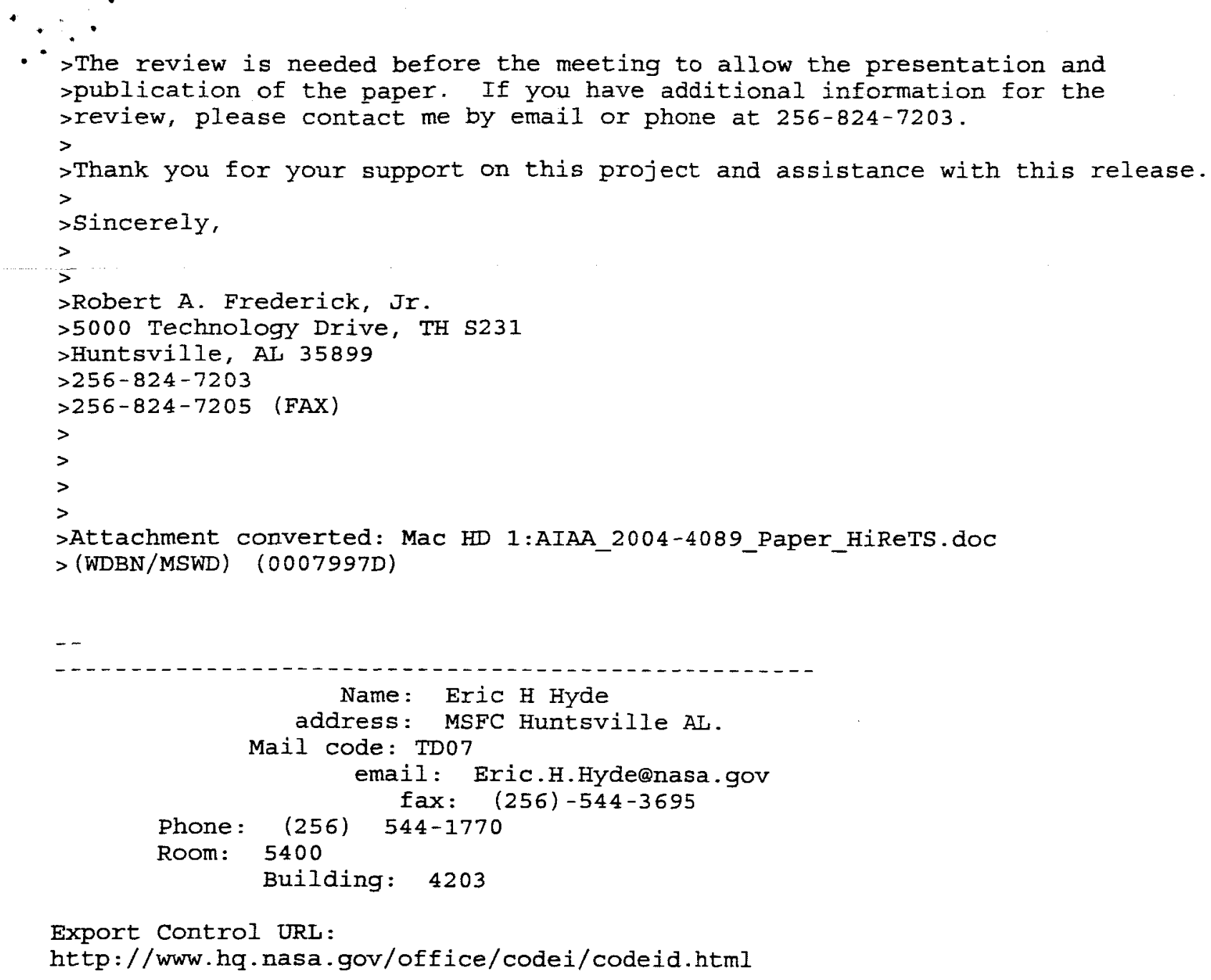

